\title{
Mobile cell phone technology puts the future of health care in our hands
}

\author{
Kumanan Wilson MD MSc
}

Cite as: CMAJ 2018 April 3;190:E378-9. doi: 10.1503/cmaj.180269

See related article at www.cmaj.ca/lookup/doi/10.1503/cmaj.170432

$\mathbf{T}$ he digital revolution has affected virtually every aspect of our lives, and health is no exception. This is particularly evident in the burgeoning area of mobile health (mHealth). A subset of the overall digital health market, which is expected to exceed half a trillion dollars in revenue by $2025,{ }^{1}$ $\mathrm{mHealth}$ refers to the use of cell phone technology to deliver health care. A linked research paper reporting on the effectiveness of a smartphone camera functioning as a de facto photoplethysmograph to evaluate the adequacy of collateral circulation in patients scheduled for cardiac catheterization via radial artery access offers an excellent example of the opportunities presented by these technologies. ${ }^{2}$ Using doppler ultrasonography as a gold standard, Di Santo and colleagues showed that the cell phone technology had superior diagnostic accuracy compared with the modified Allen test. Despite challenges in development and scale up of such technologies, there is much to be optimistic about in mHealth.

Early mHealth applications focused on the use of short message service text messaging with standard cell phones and had some promising results, particularly in low- and middle-income countries. ${ }^{3}$ The advent of smartphone technology and mobile applications has increased the potential impact and scope of mHealth dramatically. These applications are being designed for both health care providers and the public, thus empowering patients to take more control of their health care. Although the number of smartphone applications being downloaded is declining in general, health application usage has increased. ${ }^{4}$ Importantly, those who have come of age in the new millennium (millennials), among whom smartphone penetration is greatest, are the largest demographic of health application users. ${ }^{5}$ However, as the number of mHealth applications continues to increase, with over 3 billion downloads worldwide, ${ }^{6}$ challenges associated with bringing mHealth into practice have also increased. These obstacles include moving mHealth technologies from pilot studies to broader dissemination and use, determining the degree of evidence needed for widespread adoption, ${ }^{7}$ identifying the appropriate regulatory framework for these technologies and assessing how best to conduct research in an area where the technology being evaluated is constantly changing. Many of

\section{KEY POINTS}

- The advent of smartphone technology and mobile applications has increased the potential impact and scope of mobile health ( $m$ Health) dramatically, but the challenges of bringing this technology into wider practice are substantial.

- Although downloads of smartphone applications are declining in general, health application usage has increased, particularly among millennials.

- Most mHealth applications do not undergo rigorous evaluation; indeed evaluation is difficult because of rapidly developing and changing technology.

- The health care profession and regulatory agencies should proactively address the challenges associated with bringing mHealth solutions into practice to maximize their benefits.

these obstacles are present in the case of the technology described by Di Santo and colleagues. ${ }^{2}$

The findings of the linked study are promising in many respects. Cell phone technology provides an easily accessible and superior alternative to physical examination to assess radial collateral circulation. The study's authors should be congratulated for conducting a rigorous evaluation of the application of their technology, because most mHealth applications do not undergo any evaluation. As the authors point out, in addition to its potential health benefits, this technology could have important implications from a resource perspective; given the ubiquity of smartphone technology, the cost of its application would be minimal. However, like many mHealth innovations, this proof-of-concept pilot will face many obstacles to widespread clinical adoption. ${ }^{8}$

The speed of development and change in the technology being evaluated means that mHealth applications, and digital health in general, face an issue not usually encountered in evaluations of traditional pharmaceutical interventions. For example, in the linked study, the camera used was from an iPhone 4S, likely state of the art at the time. However, from the study's inception to its publication, the iPhone camera's megapixel quality increased from 8 for an iPhone $4 \mathrm{~S}$ to 12 for an iPhone X. Presumably, this change would improve the accuracy of the assessments in this 
case, but in other instances, technological changes could qualitatively alter the intervention to such a degree that the original study becomes irrelevant. For many mobile technologies, and applications in particular, development is continuous, in what is referred to as an agile process. Agile development refers to the creation of a minimally viable product and then rapidly iterating that product based on performance and feedback. ${ }^{9}$ Consequently, the product being evaluated at the outset of a trial is likely to be constantly changing, with numerous features added, removed or altered as the trial progresses. Alternative clinical trial methods, such as adaptive designs that permit iteration as the trial proceeds, may offer opportunities to evaluate such dynamic products more effectively. ${ }^{10}$

A previous analysis of US Food and Drug Administration regulatory studies showed that few $\mathrm{mHealth}$ technologies receive approval for clinical study. ${ }^{11}$ Arguably, the use of a smartphone for the purposes described in Di Santo and colleagues' study meets the standards of a medical device - a health or medical instrument used in the treatment, mitigation, diagnosis or prevention of a disease or abnormal physical condition. However, uncertainty remains over the regulatory standards governing many mHealth applications, and, as previously discussed in CMAJ, it is not clear which mHealth medical devices are low or high risk and, therefore, what the process should be for achieving regulatory approval. ${ }^{12}$

On a positive note, the linked study represents an excellent example of the democratization of innovation. With traditional pharmaceuticals, the process from idea to innovation is long and arduous, with substantial barriers to entry and low likelihood for success. Digital technology has opened up the innovation space to a whole new generation of health care entrepreneurs. Whether coming up with ingenious novel applications of existing technology on phones, taking nascent ideas to developers or hack-athons to create $\alpha / \beta$ versions, or learning coding themselves, health care providers and patients can now more easily champion innovation. These will be the people who have the best understanding of and commitment to the needs of the public.

Referred to as a new industrial revolution, the impact of digital technologies will be both disruptive and transformative. The contin- ued maturation of technologies, such as artificial intelligence, virtual reality and blockchain, will further expand the possibilities for $\mathrm{mHealth}$ in both diagnosis and treatment in health care. It is incumbent upon the health care profession to address proactively the many challenges mHealth presents to best maximize its benefits.

\section{References}

1. Digital health market revenue of US $\$ 536.6$ bn by the end of 2025: technology advancement and innovation [press release]. Albany (NY): MarketResearchReports. Biz; 2017. Available: www.digitaljournal.com/pr/3518555 (accessed 2017 Dec. 20).

2. Di Santo P, Harnett DT, Simard T, et al. Photoplethysmography using a smartphone application for assessment of ulnar artery patency: a randomized clinical trial. CMAJ 2018;190:E380-8.

3. Lester RT, Ritvo P, Mills EJ, et al. Effects of a mobile phone short message service on antiretroviral treatment adherence in Kenya (WelTel Kenya1): a randomised trial. Lancet 2010;376:1838-45.

4. Smartphone behaviour in Canada and the implications for marketers in 2016 Catalyst Canada; 2016. Available: http://catalyst.ca/2016-canadian-smartphone -behaviour/ (accessed 2018 Mar. 1).

5. Millennials are top smartphone users. New York: Nielsen; 2016 Nov. 15. Available: www.nielsen.com/us/en/insights/news/2016/millennials-are-top-smartphone -users.html (accessed 2018 Mar. 1).

6. Skardziute A. The mHealth apps market is getting crowded. Berlin (Germany): Research2Guidance. Available: https://research2guidance.com/mhealth-app -market-getting-crowded-259000-mhealth-apps-now/ (accessed 2018 Feb. 26).

7. Tomlinson M, Rotheram-Borus MJ, Swartz L, et al. Scaling up mHealth: Where is the evidence? PLoS Med 2013;10:e1001382.

8. Shuchman M. The promise and pitfalls of global mHealth. CMAJ 2014;186:1134-5.

9. Beck K, Beedle M, van Bennekum A, et al. Principles behind the Agile Manifesto. Agile Maniesto; 2001. Available: http://agilemanifesto.org/iso/en/principles. html (accessed 2017 Dec. 20).

10. Lin P-H, Intille S, Bennett G, et al. Adaptive intervention design in mobile health: intervention design and development in the Cell Phone Intervention for You trial. Clin Trials 2015;12:634-45.

11. Cortez NG, Cohen IG, Kesselheim AS. FDA regulation of mobile health technologies. N Engl J Med 2014;371:372-9.

12. Kwong W. What is government's role in medical apps? CMAJ 2015;187:E339.

\section{Competing interests: None declared.}

This article was solicited and has not been peer reviewed.

Affiliations: Clinical Epidemiology Program, Ottawa Hospital Research Institute; Departments of Medicine and Epidemiology, and Community Medicine, University of Ottawa, Ottawa, Ont.

Correspondence to: Kumanan Wilson, kwilson@ohri.ca 